\title{
UNIQUE STYLE OF RHYTHMIC LINE DRAWINGS BY K. K. HEBBAR
}

\author{
Dr. Archana Rani 1 $1 \square$ \\ Head and Associate Professor, Drawing and Painting Department, R.G. (PG) College, Meerut, India \\ Head and Associate Professor, Drawing and Painting Department, R.G. (PG) College, Meerut, India
}
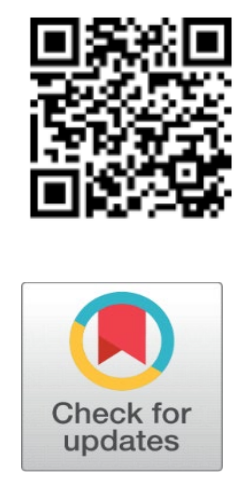

\section{ABSTRACT}

Kattingeri Krishna Hebbar was born at Kittingiri in the Udupi district of Karnataka. In his childhood he played with clay and tried to form toys out of it. He also tried to draw with charcoal on the wall of his house the copies of the mythological pictures of Ravi Varma. This inclination towards drawing resulted into his entry in the Chamrajendra Vadiar Technical School for the study of painting. While watching Indian classical dance, he was attracted by the graceful movements of the body and the limbs of the dancer. He expressed in lines on his sketching pad, often without even his looking at the result on paper. His hand started moving automatically, charged with emotion, and guided by music. In this process the flow of line was all that mattered.

Keywords: Music, Rhythm, Drawings, Unique, Soul, Expression, Creation

Received 17 December 2020

Accepted 02 February 2021

Published 24 February 2021

CorrespondingAuthor

Dr. Archana Rani,

drarchana.art@gmail.com

DOI

10.29121/shodhkosh.v2.i1(SE).2021. 14

Funding: This research received no specific grant from any funding agency in the public, commercial, or not-for-profit sectors.

Copyright: (C) 2021 The Author(s). This is an open access article distributed under the terms of the Creative Commons Attribution License, which permits unrestricted use, distribution, and reproduction in any medium, provided the original author and source are credited.

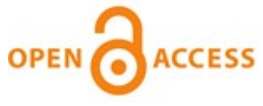

\section{INTRODUCTION}

Line drawing in any image that consists of distinct straight or curved lines placed against a background, without gradation in shade or colors to represent two-dimensional or three-dimensional objects. Before the development of photography and of halftones, line drawing was the standard format for illustrations to be used in print publications, using black ink on white paper.

One of the most fundamental elements of art is the line. An important feature of a line is that it indicates the edge of a two-dimensional shape or a three-dimensional form. Line is the most basic design tool on which almost every piece of art relies. A line has length, width, tone, and texture. It may divide space, define a form, describe contour, or suggest direction. One can find a line in every type of art. There are, of course, line drawings and even the most abstract painting uses line as a foundation. Without line, shapes cannot be noted, texture cannot be suggested, and tone cannot add depth.

\section{PURPOSE AND IMPORTANCE OF RESEARCH PAPER}

The beauty of lines is well known in Indian art. Lines have been used as a tradition in Indian art. From the point of view of purpose and importance, the writer has tried to tell that there are expressions in the picture only through the lines that generate rasa and rhythm. Presently, painters are creating paintings with this spirit, and it will continue to recur in future. Throughout art 
history, artists have created influential art using the line as a principle means of visual expression and it's often thought that an artist's stroke is the purest way to perceive their abilities. As a line winds across a paper or canvas, this continuous band can emit powerful emotions. K.K. Hebbar was a gifted draughtsman among his other talents. His line drawings became prized art pieces Hebbar (2003). Hebbar produced rich drawings that continue to influence artists. K.K. Hebbar developed a single line drawing technique that was able to depict the very essence of his subject matter in only one opened line.

\section{PROCESS OF RESEARCH PAPER}

The main element of Indian art is line, through which various arts connected with different emotions have been born. Rekha is the inspiration for the most prominent expression that the primitive man carved on the reefs of the caves. The language was born through this line of expression. The full lines from the language were the silent voice of man. Therefore, line Precedence has been made the basis of research paper by studying the beauty of the line used in the arts of various periods for writing this paper. In order to present the paper in a systematic manner, the definition of the line, explaining the meaning, describing its importance and features, the beauty of ancient art, and the diverse lines used in modern artist K.K. Heber. Of course, the one-line K.K. Heber drawings became the inspiration for many artists and designers. Hebbar's drawings help us to appreciate his natural, artistic talent. Hebbar's genius brought about so much in his drawings, with often just a single, well-thought-out line in pencil or pen. The simplicity was astounding and helped others to realize the talents that lied in abstraction. Sharma (1991)

\section{REVIEW OF RESEARCH PAPER}

Literature is the backbone of any paper. In which the work of paper-writing and data compilation is done first. Therefore, the research paper writer written on the basis of her study, teaching experience has been included. which books are implemented for writing this research paper are - Agrawal (2016) 'Kala-Vilas', Manohar Kaul's 'Tradition of Indian Art ', Dr. Prem Shankar Dwivedi's 'Rajasthani painting', Hebbar (1974) 'An Artist's Quest', New Delhi, Abhinav Publication, 1974; Hebbar (1990), 'Voyage in Images', Bombay, Jehangir Art Gallery, 1990; Anand (2003) 'The Singing Line', Bombay, western Printers and Publishers, 1964? as well as research articles have also been contemplated. whose authors views have been given prominence in writing this paper, there list is given under references at the end of research paper writing. Priya (2015)

\section{IMPORTANCE OF LINES}

The original form of Indian art is notation by the line. The lines are considered the ornament of a picture. The form is created by the line itself. The importance of line from the prehistoric period to today is undeniable. Indian painters specialize in creating expressions through lines. Apart from creating emotion, they also give pleasure to the spectators. Artists from prehistoric times to the present day have been skilled and qualified in lines. Artists, with their unbreakable and rhythmic lines have engraved various subjects on the various spaces. Hebbar (1993)

In fact, line is the soul of an artwork. By discovering the potential of the line, artists have made every effort to express the powerful motion of different shapes 
and objects. Line is the only stanza of life and there is also the life of the picture. That is why Acharyas have also praised Rekha Karma. The ultimate goal of liveliness of the picture can be understood well only by the existence of the line. The integrity of the picture, unity, uniqueness, and liveliness emerges in the picture. Rani (2014)

\section{BEAUTY OF LINES IN TRADITIONAL ART}

Various lines in Indian art hold their special place due to their fundamental characteristics. Lines are not just shape-defining, but dynamic and strong lines are expressive as well as creative. Indian art has been depicted by lines from the primitive era to the contemporary period. But the lines have been used in the art of each period due to their personal characteristics, with slight differences. Just as the lines in Ajanta cave paintings are softness, lyrical sentimentality, while in medieval art, the lines do not have tenderness, elasticity, emotion like Ajanta. The beauty of lines is supernatural in Mughal art with Iranian art style. In the Apabhramsa style paintings, the lines are rigid and congenial. Vishwakarma (1962) The lines have their own specialties in different sub-styles of both Rajasthani and Pahari art styles. In the Kangra style paintings, there are visions of rhythm, verses, sweetness, tenderness in the forms by lines. In Bengal school, the lines are beautifully taken. The modern era is an era of individualism and freedom. Therefore, in today's art, artists are using the lines in their own way to awaken different emotions. Therefore, there has been a difference in the use of lines in art due to various experiments. But the truth is that even today artists are drawing pictures through lines and will continue to do so in future. Shukla (1962)

\section{RHYTHMIC LINE DRAWINGS BY K.K. HEBBAR}

Katingeri Krishna Hebbar was born in 1911 at Kattingiri in The Udupi district of Karnataka. South Kanarain 1911. He was inclined towards art from childhood because of his father, who was a part time clay sculptor, occasionally making Ganesh idols. After some initial training in Mysore, he pursued art and was formally trained at the Sir J.J. School of Art, Mumbai, where he was awarded a diploma in painting. Das (1997) After teaching there briefly, Hebbar also did a course at the Academic Julian in Paris in the year 1949-50. Artists despite training in the Western tradition, Hebbar's body of work remained rooted in the folk traditions of India. His early paintings of landscapes and figure compositions disciplined him and made him create his own unique style, rhythm, and colour. To understand rhythm, he even learnt the dance form of Kathak. Rani (2017)

Heber was also inspired by the illustrations of Jain manuscripts, Mughal miniatures, and Ajanta murals. He was also highly influenced by Paul Gauguin and Amrita Sher Gill. In his work, he harmoniously blended the traditional Indian forms with elements of Western art such as surrealism and abstract art. He was inspired by music and dances like Kathak and captured the grace of the dancers and performers in his paintings. Rambhatt (1984).

Hebbar served as the chairman of the Artists' Centre, Mumbai from 1953-73. In 1976, Hebbar became a fellow of Lalit Kala Akademi, Hebbar was honored with a number of awards through his career, including the highest civilian awards Padma Shri in 1961, Padma Bhushan in 1989. Gupta (1967)

Hebbar mostly chose Yakshagana (a traditional dance form in Karnataka), Kambla (an annual buffalo race), bhoota kola (ancient ritual form of worship), cock 
fight and other rural sports and folk arts in his line drawings. Line drawings are now synonym with his name and this unique style has become his brand. Throughout his career, Hebbar never ceased to experiment, and enriched his artistic vocabulary through several trips around the country, including those to important historical sites like the ancient caves at Karla, in Maharashtra. One of the sketches that resulted from this particular trip won him a gold medal from the Bombay Art Society. Rani (2012)

The most impressive part of Hebbar's oeuvre are his line drawings stretching across the 1950s, 1960s and 1970s. in a few lines he is able to fill out a figure which is alive and almost jumping out of the paper on which it is drawn. The fifty-one drawings he has done for the ancient Tamil epic, Silappadikaram are pure magic. Agrawal and Agarwal (1996)

Hebbar started drawing Indian sculptures which adorn famous monuments. In these drawings, he eliminated the details but retained the rhythmic quality that ran through these figures. In this process of emphasizing rhythm, he simplified the form, drawing at times without lifting the pen and leaving out the parts which obstructed this basic aim. He also began to exaggerate or distort certain parts. He tried to obtain the maximum effect with minimum lines, thus establishing his individuality. Marishamachar (1983)

Actually, Line drawing is any image that consists of distinct straight and curved lines placed against a plain background and is usually monochromatic. It emphasizes form and outline, over colour, shading, and texture. As Paul Klee beautifully puts it, "A Drawing is simply a line going for a walk". And think of line drawings, and the first illustration which comes to one's mind is probably that of K.K. Hebbar. Hebbar (1968) He used minimum simply lines without shade to convey more. Facial expressions of his line drawing works were not static but lively. In the beginning, Hebbar used to draw with the intention of reproducing the object of his choice. Even while painting an object or a scene, he used to draw the contour with pencil, pen or charcoal and then used colour to get verisimilitude. As he gained proficiency in recording what he wanted in lines, he gradually acquired a style of his own. So far, his aim was to reproduce accurately what he saw or imagined. But once achieved that skill, he started searching the hidden beauty in the interplay of lines, the evocative quality of straight and curved lines. This quality of rhythmic movement of lines began to engage his attention more and more.
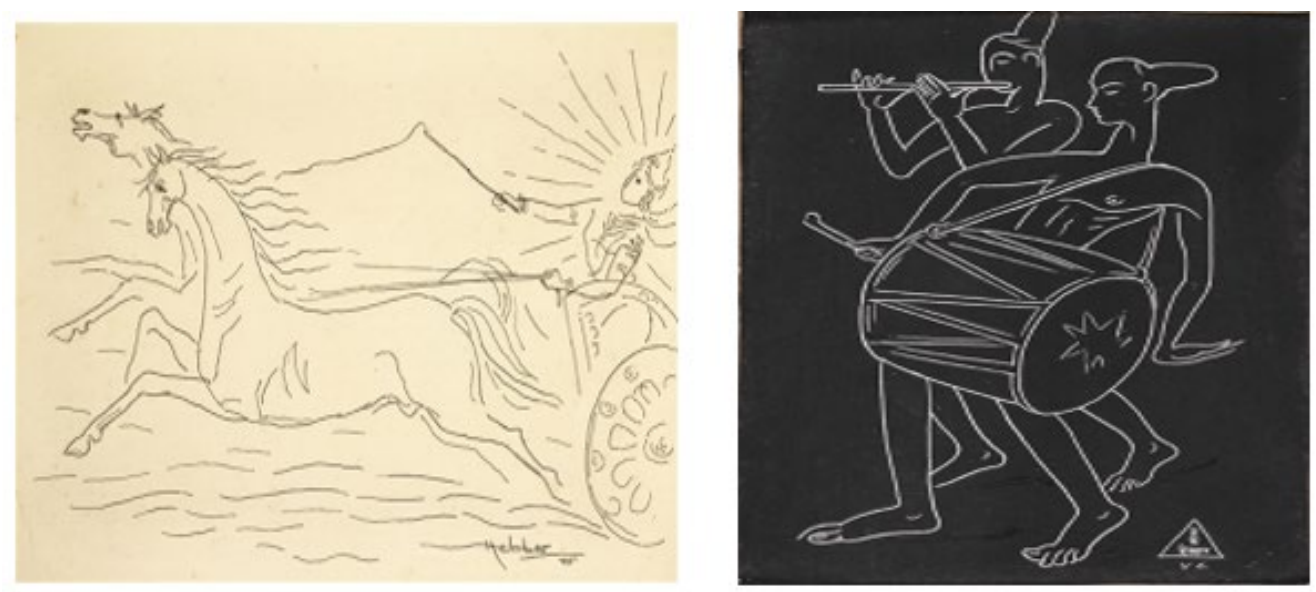

Figure 1 Picture by K. K. Hebbar 

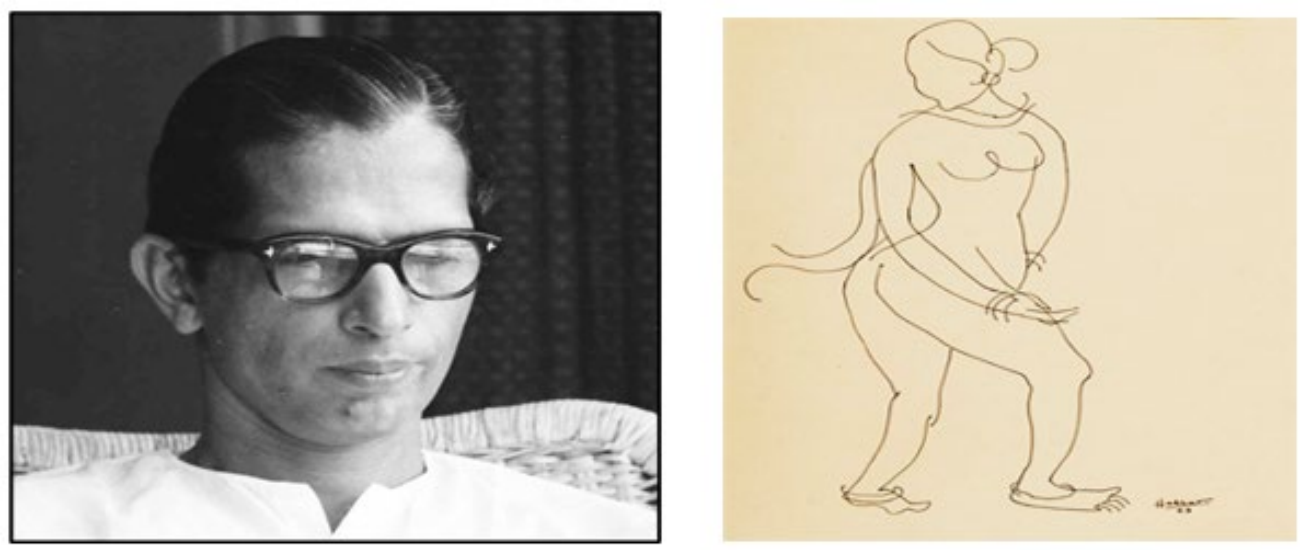

Figure 2 Picture by K. K. Hebbar
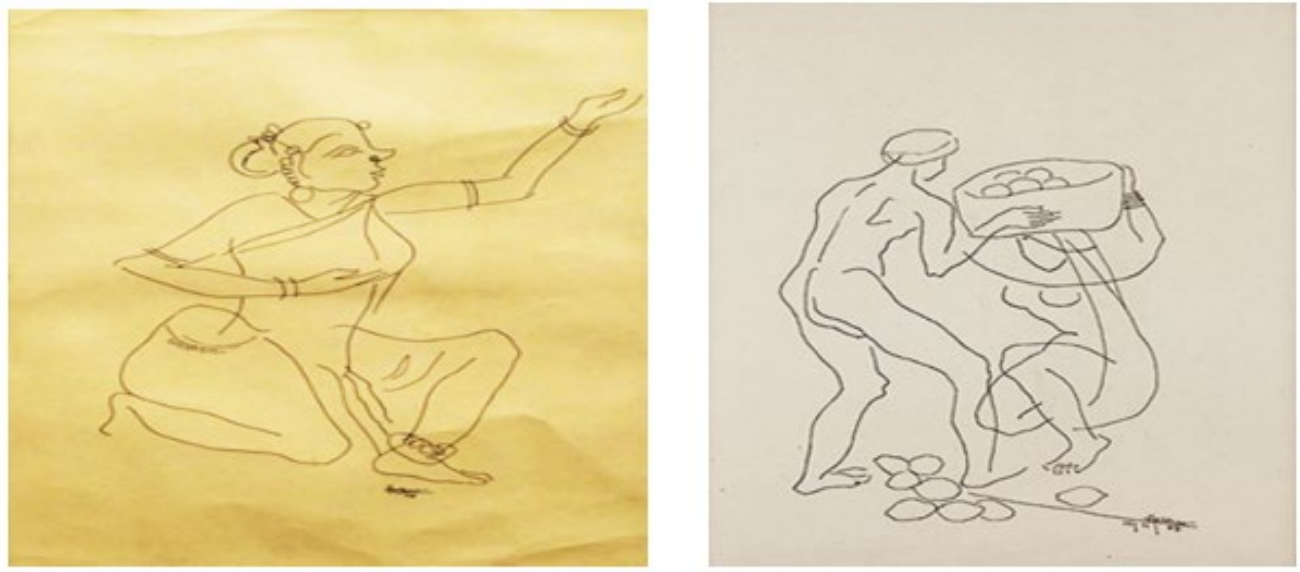

Figure 3 Picture by K. K. Hebbar
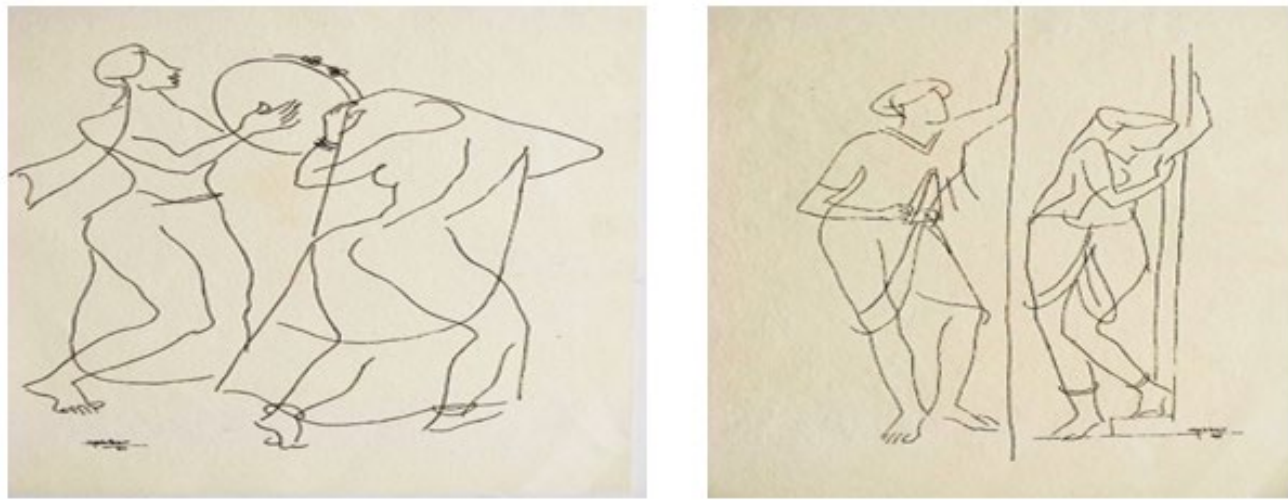

Figure 4 Picture by K. K. Hebbar 

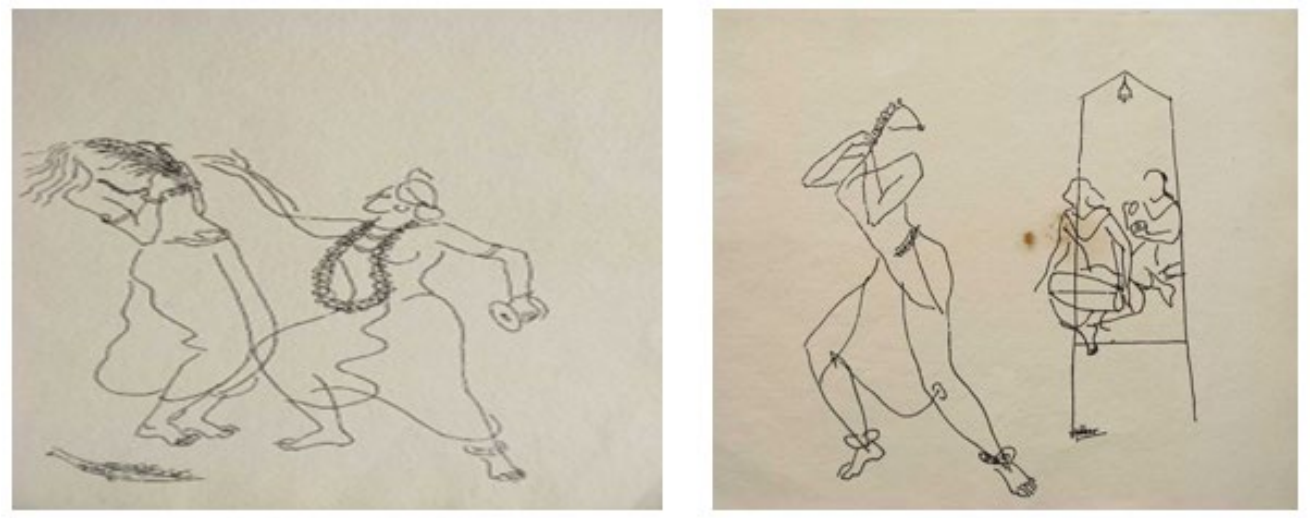

Figure 5 Picture by K. K. Hebbar

\section{EPILOGUE AND CONCLUSION}

India has its own glorious culture and traditions. Line has been used as a tradition in Indian art, which will continue to be done in the same way in future. It is also true that experimentation is an essential part of life, but it is necessary to take care of Indianness while using it in art. In other words, while doing new experiments, you should also be inspired by your traditional and modern art. In fact, Indian art has taken an idealistic form, in which communication of emotions, rhythm, tempo and intensity as well as the origin of rasa has been possible only through lines. In essence, if the skill of lines is found in any art, it is Indian art. The lines are the soul of Hebber's drawings. To sum up, Hebbar made drawings by never taking his pens off the paper. Thus, he created beautiful drawings with just one continuous line.

\section{REFERENCES}

Agrawal, R. A. (2016). Kala Vilas Bhartiya Chitrakala ka Vivechan. Hindi Pracharak Library. https://www.mycoursebook.in/kala-vilas-bhartiya-chitrakala-kavivechan-ra-agrawal-international-publishing-house.html

Agrawal, S. B. and Agarwal, M. (1996). History of Indian Painting (Part-1). Allahabad : Rup Shilp Publications.

Anand, M. J. (2003). The Singing Line Drawings By Hebbar. Abhinav Publications. https://www.amazon.com/Singing-Line-Drawings-Hebbarebook/dp/B0040EIDL6

Das, K. (1997). Introduction to Indian Art. Lucknow : Uttar Pradesh Hindi Granth Academy.

Gupta, J. (1967). Prehistoric painting. Delhi : National Publishing House.

Hebbar, K. K. (1968). Folder of Exhibition Held [Exhibition]. Bonython Art Gallery, Sydney, Australia.

Hebbar, K. K. (1974). An Artist's Quest. New Delhi : Abhinav Publication. https://books.google.co.uk/books/about/An_Artist_s_Quest.html?id=JzxQ AAAAMAAJ\&redir_esc $=y$

Hebbar, K. K. (1990). Voyage In Images [Exhibition]. Jehangir Art Gallery. Bombay, India. 
Hebbar, K. K. (1993). Exhibition of Paintings [Exhibition]. Delhi : Vadehra Art Gallery, New, India.

Hebbar, K. K. (2003). Tulsidas : Hebbar's Narration in Lines. Delhi : Abhinav Publication. https://amzn.to/301VG00

Marishamachar, N. (1983). Hebbar. Bangalore : C.M.N. Prakashana. http://aaabibliography.org/SeeMore/4792

Priya, K. (2015). Drawing The Line. Delhi : Ad Astra Comix. https://www.amazon.com/Drawing-Line-Priya-EditorKuriyan/dp/0994050712

Rambhatt, B. (1984). Kala Vaibhav, Ajanta Ellora. Delhi : Alankar Publications.

Rani, A. (2012). Contemporary Art, Miscellaneous Landscapes. Meerut : Raghunath Girls (PG) College (Publisher).

Rani, A. (2014). Traditional Drawing (2nd ed.). Meerut : Krishna Prakashan. https://www.krishnaprakashan.com/indetails.asp?id=1127

Rani, A. (2017). Shringar and Beauty in Pahari Art. Delhi : Swati Publications.

Sharma, L. C. (1991). Brief History of Indian Painting. Meerut : Goyal Publishing House. https://amzn.to/3LWihcQ

Shukla, R. (1962). Rectification of painting. Varanasi : Hindi Pracharak Library.

Vishwakarma, R. (1962). Indian Painting. Allahabad: Vishwanlal Marg and Sons. 